
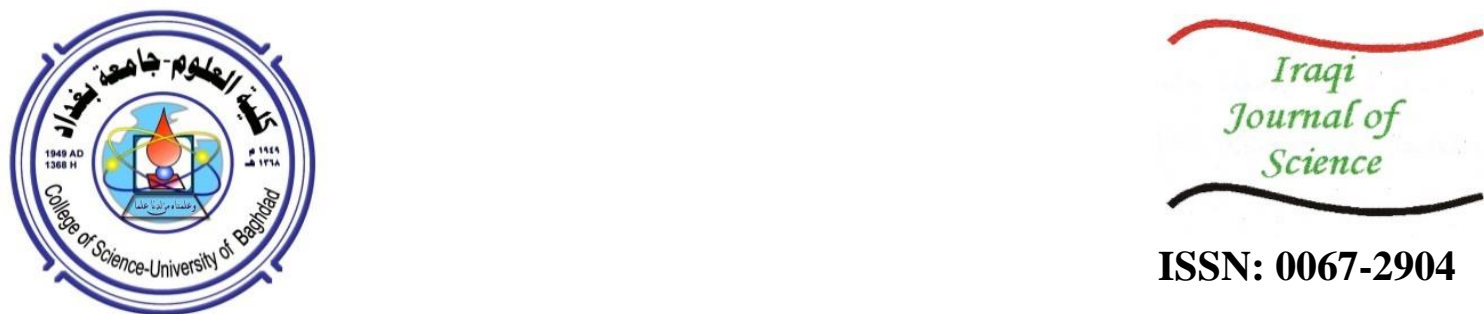

ISSN: 0067-2904

\title{
2D Seismic Structural and Stratigraphic Study of Kirkuk Group Formation in Amara Oil Field- Southeastern Iraq
}

\author{
Ali K. Jaheed ${ }^{1 *}$, Hussein H. Karim ${ }^{2}$ \\ ${ }^{I}$ Department of Geology, College of Science, University of Baghdad, University, Baghdad, Iraq. \\ ${ }^{2}$ Professor, Civil Engineering Department, University of Technology - Iraq, University, Baghdad, Iraq
}

Received: $19 / 3 / 2021$

Accepted: $23 / 5 / 2021$

\begin{abstract}
The Amarah Oil field structure was studied and interpreted by using 2-D seismic data obtained from the Oil Exploration company. The study is concerned with Maysan Group Formation (Kirkuk Group) which is located in southeastern Iraq and belongs to the Tertiary Age. Two reflectors were detected based on synthetic seismograms and well logs (top and bottom Missan Group). Structural maps were derived from seismic reflection interpretations to obtain the location and direction of the sedimentary basin. Two-way time and depth maps were conducted depending on the structural interpretation of the picked reflectors to show several structural features. These included three types of closures, namely two anticlines extended in the directions of S-SW and NE, one nose structure (anticline) in the middle of the study area, and structural faults in the northeastern part of the area, which is consistent with the general fault pattern. The seismic interpretation showed the presence of some stratigraphic features. Stratigraphic trap at the eastern part of the field, along with other phenomena, such as flatspot (mound), lenses, onlap, and toplap, were detected as indications of potential hydrocarbon accumulation in the region.
\end{abstract}

Keywords: 2-D seismic, Kirkuk Group Formation, Al-Amarah oil field

دراسة زلزالية تركيبية و طباقيه ثنائية الابعاد لتكوين مجموعة كركوك في حقل العمارة النفطي- جنوب شرق العرلق

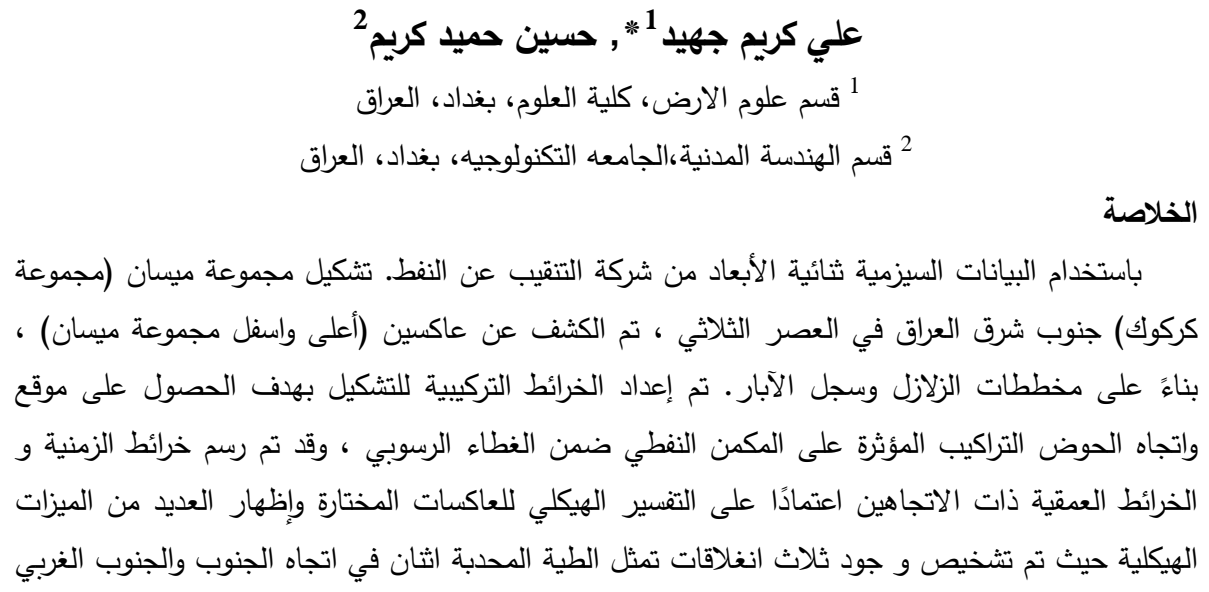




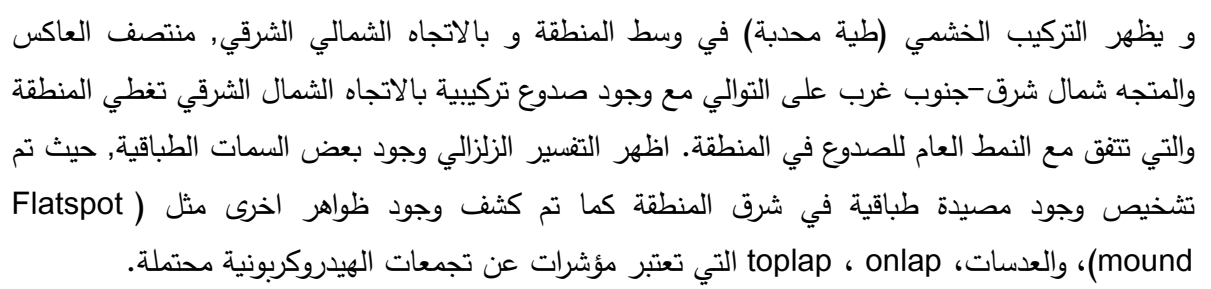

\section{Introduction}

Seismic methods are the most commonly used, especially when the seismic reflection method is applied to explore and investigate subsurface deposits of hydrocarbon accumulation [1]. Seismic reflection provides more depth information with high detail and precision, through seismic section layers of subsurface rock sequences [2].

The seismic interpretation is the last step after field data processing. The seismic data provides good visualization for the different properties and density of subsurface rocks, through the determination of the acoustic impedance of the rock layers [3]. In seismic reflection studies, the identification of accurate subsurface geological structures, like folds and faults, and stratigraphic attribute subsurface conditions, representation of data, representation in the seismic selection, velocity, time could be used to determine structural traps, stratigraphy traps, depositional environmental, facies and direct hydrocarbon indicator (DHI) [4]. Synthetic seismogram modelling gives a detailed diagram of the geological analyses, by matching formation limits obtained from wells, velocity values, and their relationship with depth in order to identify the hydrocarbon content [5].

The aim of the current study is the exploitation of seismic reflection data of Kirkuk group formation of Amarah field to determine the content of hydrocarbon and visualize structural and stratigraphic features.

\section{Location of Study Area}

The Amarah Field is located to the southwest of Maysan city, about $17 \mathrm{~km} \mathrm{SW}$ of Noor Field, $24 \mathrm{~km} \mathrm{E}$ of Al-Rafedain structure (Abu-Amoud structure), about $32 \mathrm{~km} \mathrm{SE}$ of AlKumait structure, and $12 \mathrm{~km} \mathrm{NW}$ of the Halfaya Field (Figure 1) [6]. Historically, the oilfield site was first explored in the late 1970s, during seismic surveys conducted in Maysan Province. Seismic surveys in two dimensions (2D) covered the study area. The first was carried out by the Basrah Oil Company in 1958, when the seismic data revealed that the Amarah Formation is a patchy closure, while the second was carried out by The Iraqi National Oil Company in 1974,. The outcome was represented by the well AM-1, the first dug well in the region in 1981 [7]. The study area is delineated by the coordination points A, B, C and D. Table 1 shows the geographic coordinates of the study area.

Table 1- Coordinates of the study area.

\begin{tabular}{|c|c|c|}
\hline Corner symbol & $\mathbf{X}(\mathbf{m}) \mathbf{E}$ & Y (m) $\mathbf{~}$ \\
\hline A & 685609 & 3529700 \\
\hline B & 707936 & 3529700 \\
\hline C & 708045 & 3504541 \\
\hline D & 686044 & 3504759 \\
\hline
\end{tabular}

\section{Geological and Tectonic Settings of the Area}

The quaternary fluvial sediments of the Tigris and Euphrates rivers cover the whole Mesopotamian Plain [8]. Progressive thickening shows up from the northwest to southeast, with a maximum thickness of $180 \mathrm{~m}$ near Basrah city [9]. An explanatory study has been carried out on Kirkuk group formation in the field of Amarah at the south-eastern part of Iraq, where the 2D seismic survey extended to about $1752 \mathrm{Km} 2$. This paper is named Maysan Group formation ratios for the region. A great difference was shown in the composition of the 
formation's deposits, which are made of a mixture of sand and carbonate layers, as compared to the formation in northern Iraq. is the formation is considered to be composed of sand layers that represent an extension of the Ahwaz formation in western Iran.

Tectonically, the Amarah oil field is located in a sedimentary basin within the Mesopotamian basin, which covers most of the central and southern parts of Iraq, at the eastern unit of the stable shelf represented by Tikrit - Amarah Subzone [10]. The foredeep contains several structures, including faults, folds, and diapiric structures that are almost entirely concealed beneath the Quaternary deposits. The folds are trending Northwest -Southeast, East-West, and North-South. Consequently, and due to the uplift motion of the High Folded Zone and the inclination of the West Arabian Plate, the interplate basin became narrower during the Oligocene [11]. Therefore, a great sea-level drop was witnessed, along with the Neo-Tethys closed with the collision between the Eurasian Plate and the Afro-Arabian Plate. The initiation of the Red Sea Rifting took place, along with the seafloor spreading of the Gulf of Aden. The deposition of the formations in Iraq forms a complex reef system [12].

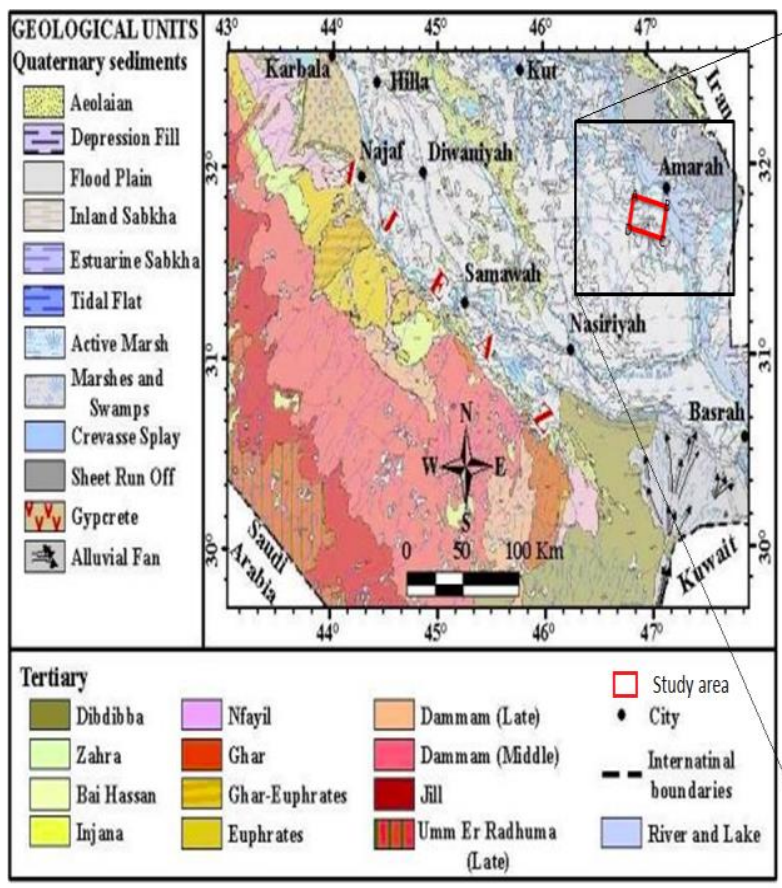

Figure 1- The location and geological map of the study area [13].

\section{Data loading and base map preparation}

1. By combining the UTM and seismic data in the SEG-Y format, the base map was created to depict the boundaries of study area and well positions. The first and last inline numbers, as well as the first and last cross line numbers, were all entered (Figure 2). The following steps were used to evaluate data from the 2D seismic surveys conducted in the study area by the Oil Exploration Company, using the Petrel seismic program. First, the 2D seismic data were utilized to prepare maps in order to clarify patterns of elevation and classify them through structural and stratigraphic images from the top and bottom of Kirkuk Group Formation (time, velocity, and depth maps). Second, seismic attributes (acoustic impedance, instantaneous phase, and alterative automatic gain control (AGC)) were used to investigate the hydrocarbon index within the top and bottom of the Formation. 


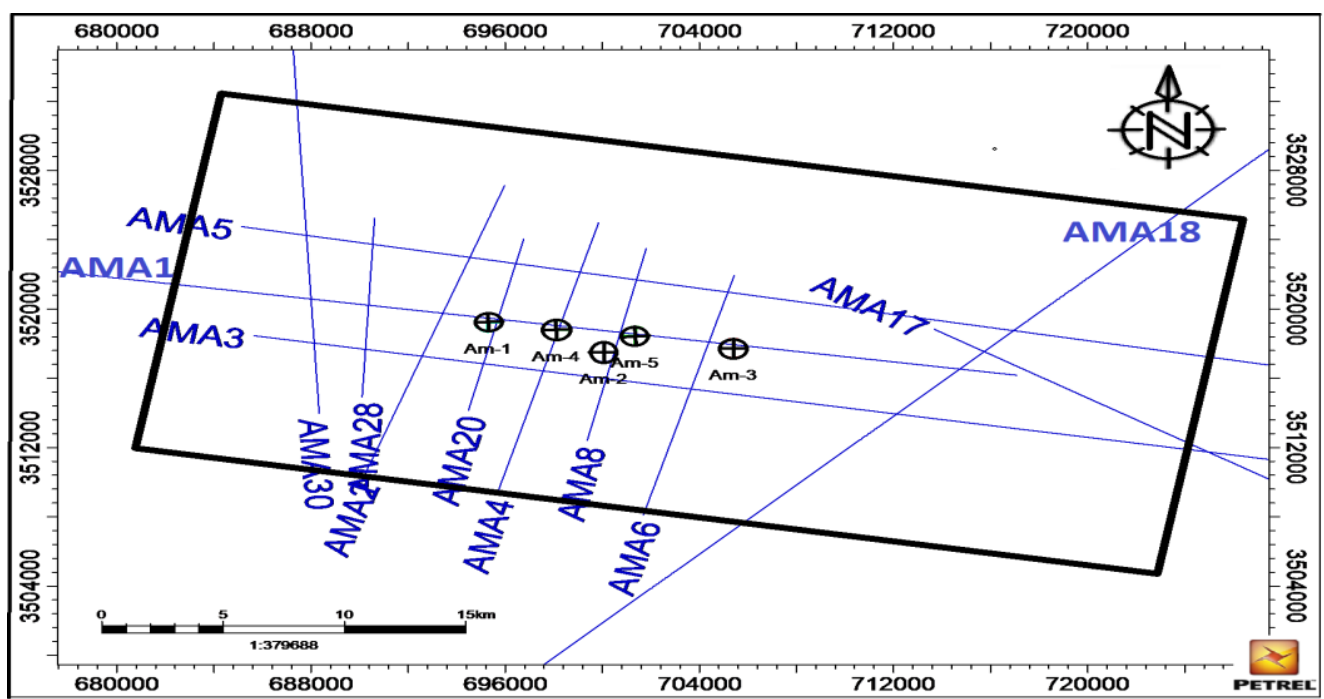

Figure 2- The base map, seismic lines, and the tied wells in the study area.

\section{Generation of Synthetic Seismograms}

The sonic calibration process, which involves calibrating the sonic and velocity logs, was the first step. We used an approximate check-shot from the Amal well because it produced the best match with the seismic portion. The second phase was the acoustic impedance which was calculated by multiplying the caliborated sonic log value by the estimated density log value. Then, the reflection coefficient was calculated. The seismic section and the synthetic seismogram showed a good match. On a synthetic trace (positive and negative reflections), the selected reflectors appeared at the top and bottom of Kirkuk Group, corresponding to the peak, but with varying intensities due to the different frequencies (Figure 3).

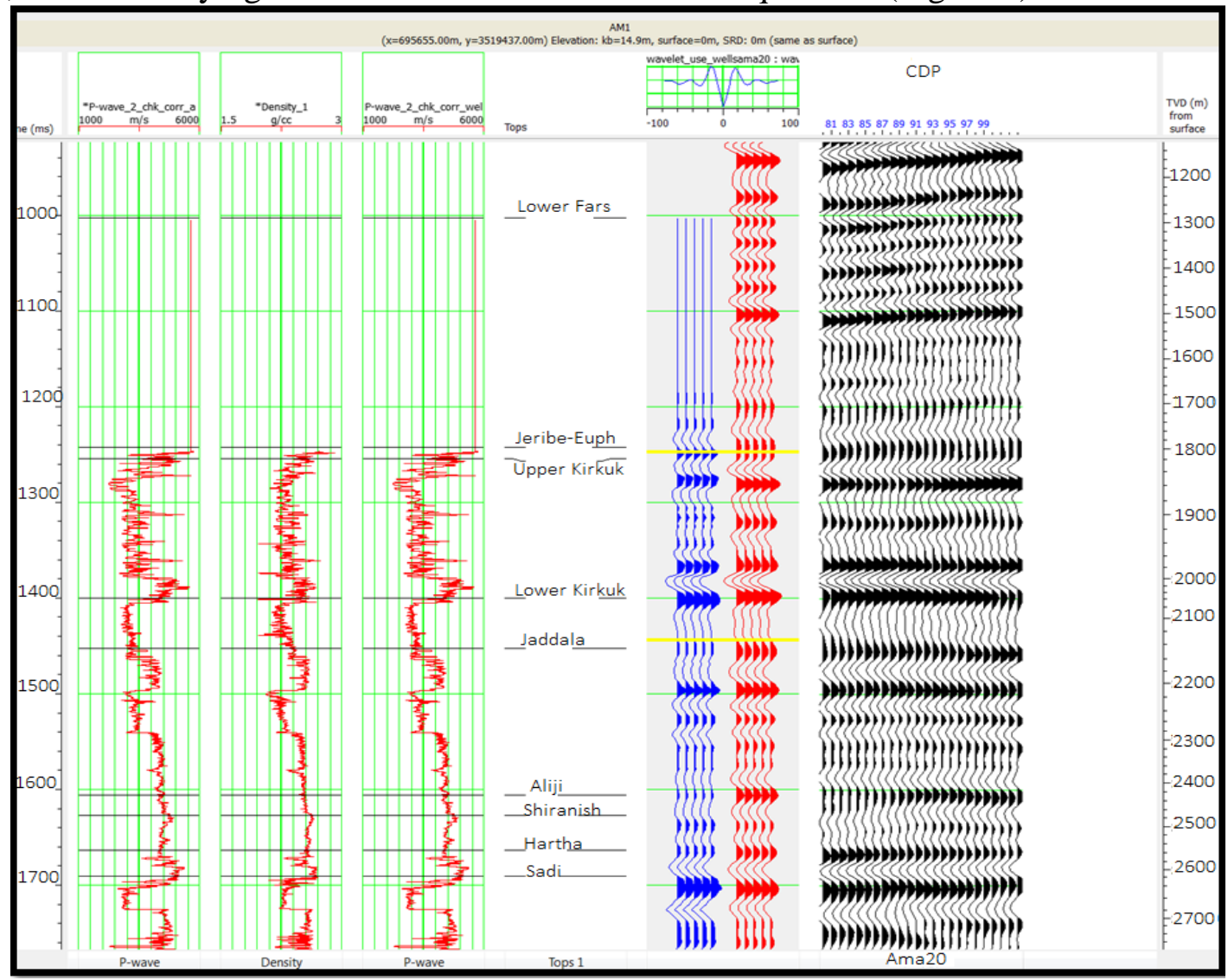

Figure 3- Synthetic seismogram and its required parameters of Am1 well. 


\section{Structural Interpretation}

The search for structural traps that contain hydrocarbons is the primary application of seismic structural analysis. The velocity data and reflection times could be converted into depths in order to create structural maps [14].

The obtained map depicts the two-way time (TWT) of the top of the Kirkuk reflector. It shows a gradual difference in time with a contour interval of $10 \mathrm{~ms}$ from the lowest time in the southwest $(1200 \mathrm{~ms})$ to the highest time in the east $(1480 \mathrm{~ms})$ (Figure 4). The two-way time analysis of the bottom of Kirkuk reflector shows that the highest value is at the N-E (1720 ms), which gradually decreases to reach the lowest value at the $\mathrm{S}$ and $\mathrm{S}-\mathrm{W}(1320 \mathrm{~ms})$. The formation was also shown to contain some structures, as shown in Figure 5. Through the time maps of the two boundaries, faults with $\mathrm{N}$ and $\mathrm{N}-\mathrm{E}$ directions appeared, which are identical to the general direction of the faulting systems in the region.

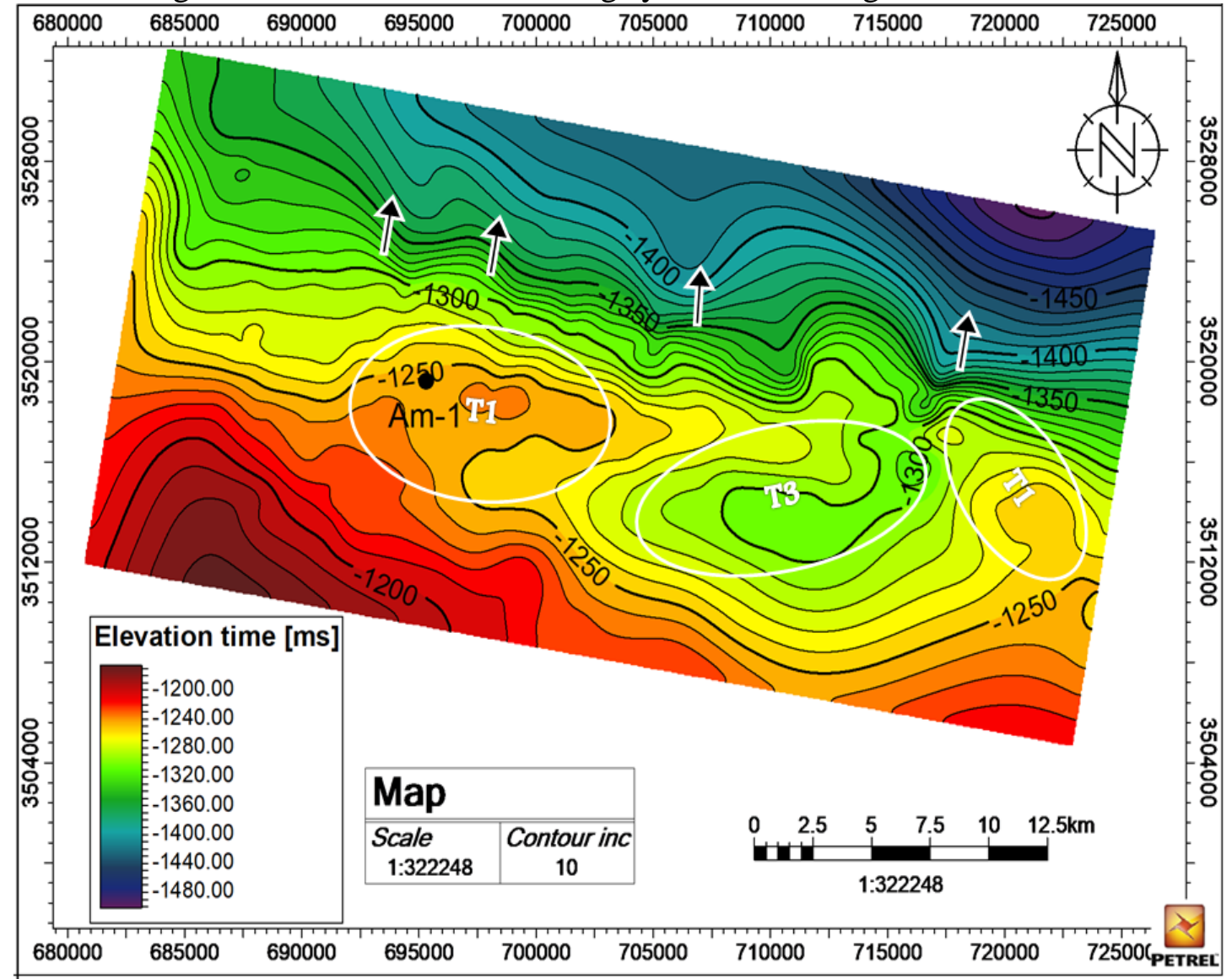

Figure 4- TWT map of Upper Kirkuk Formation. 


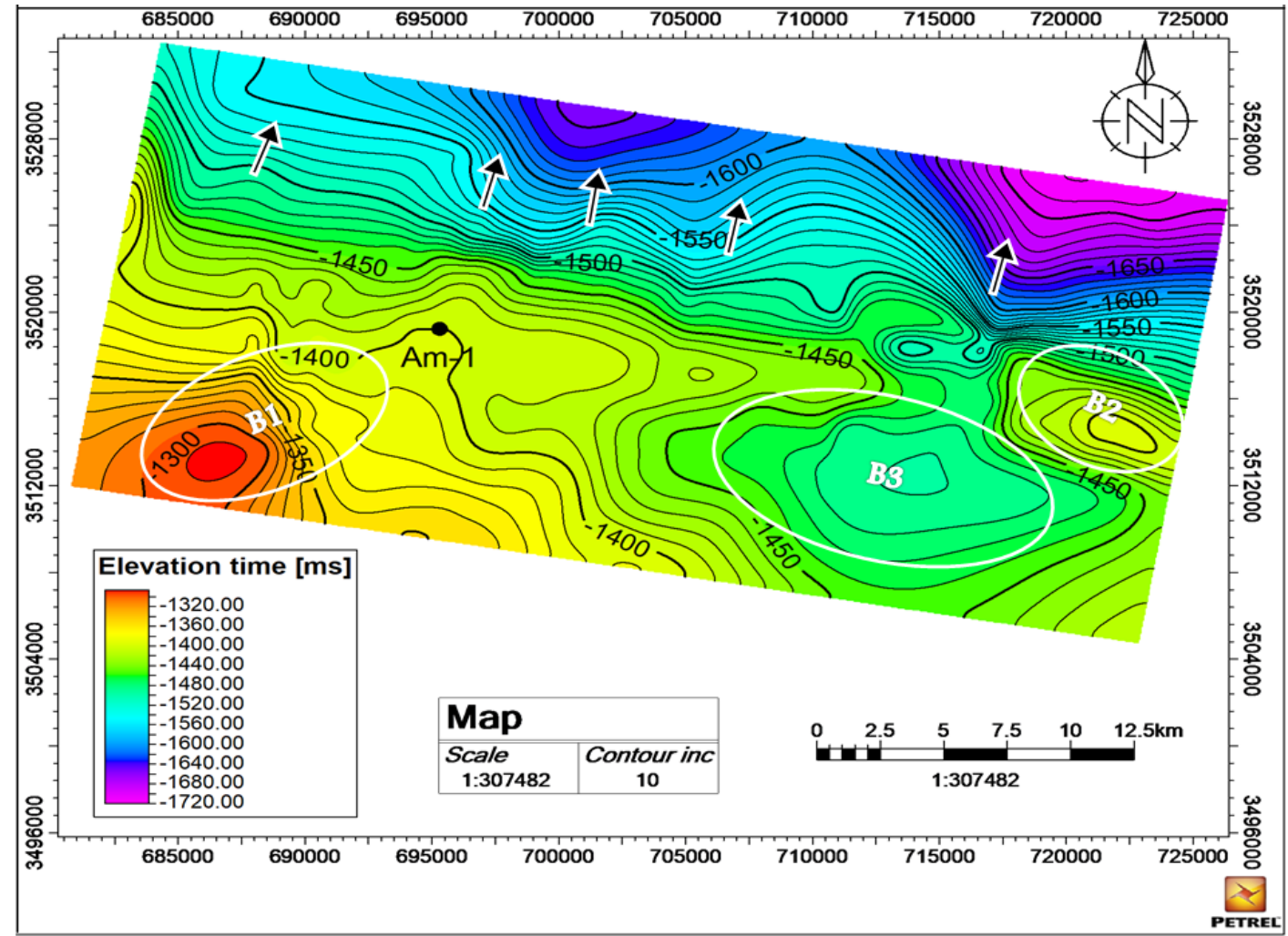

Figure 5- TWT map of Lower Kirkuk Formation.

Both depth maps display almost identical structuring. The top and bottom of Kirkuk structures in the maps show deepening towards the NE direction. As shown in Figures 6 and 7, the highest value in the area is $2480 \mathrm{~m}$, which decreases in the southwest to $1960 \mathrm{~m}$. The time and depth maps of the upper (T) and lower (B) Kirkuk structures included three anticlines, which are (T1 and B1), (T2 and B2, and the anticline of the nose structure(T3 and B3)

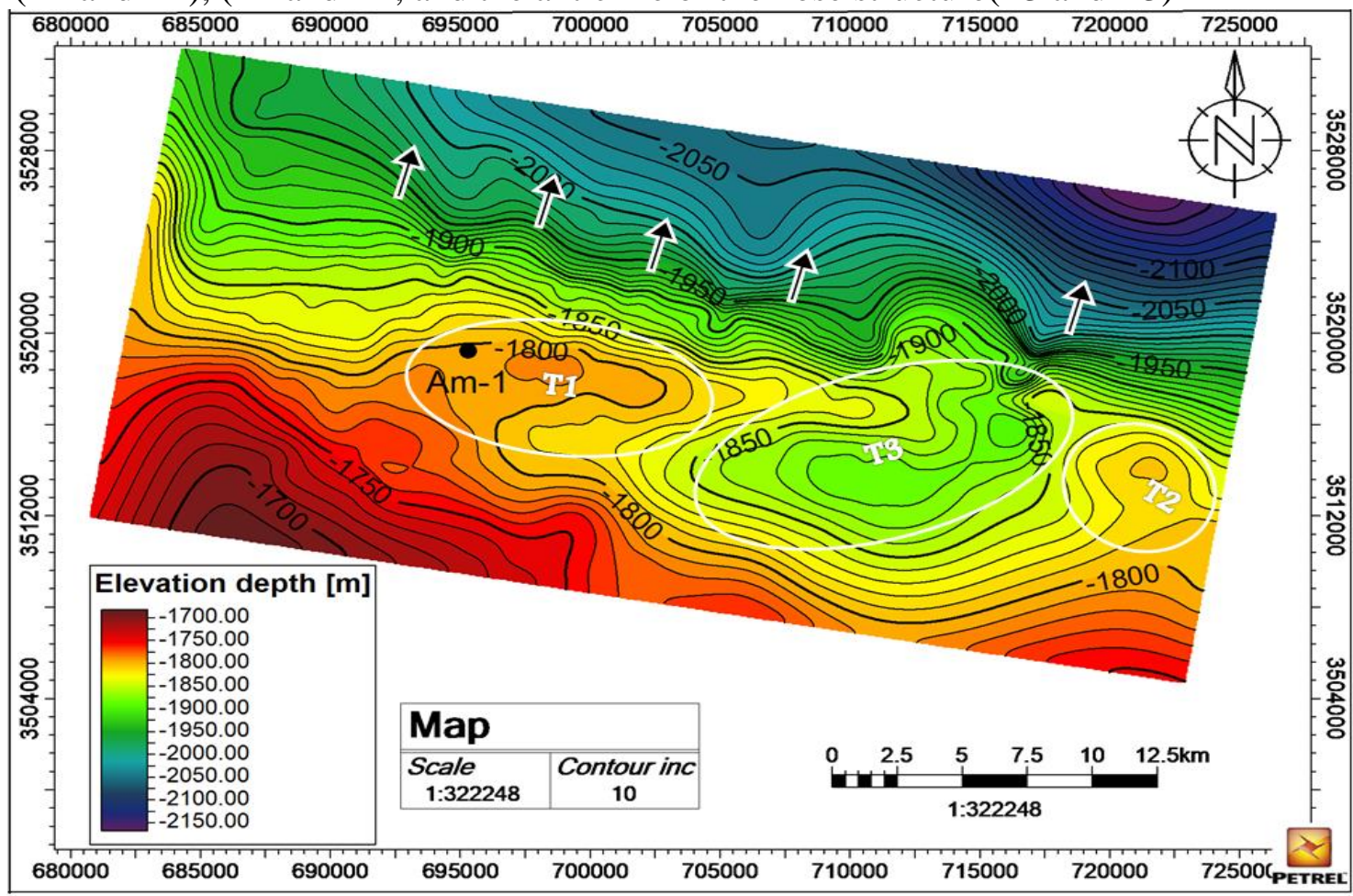

Figure 6- Upper Kirkuk Formation depth map 


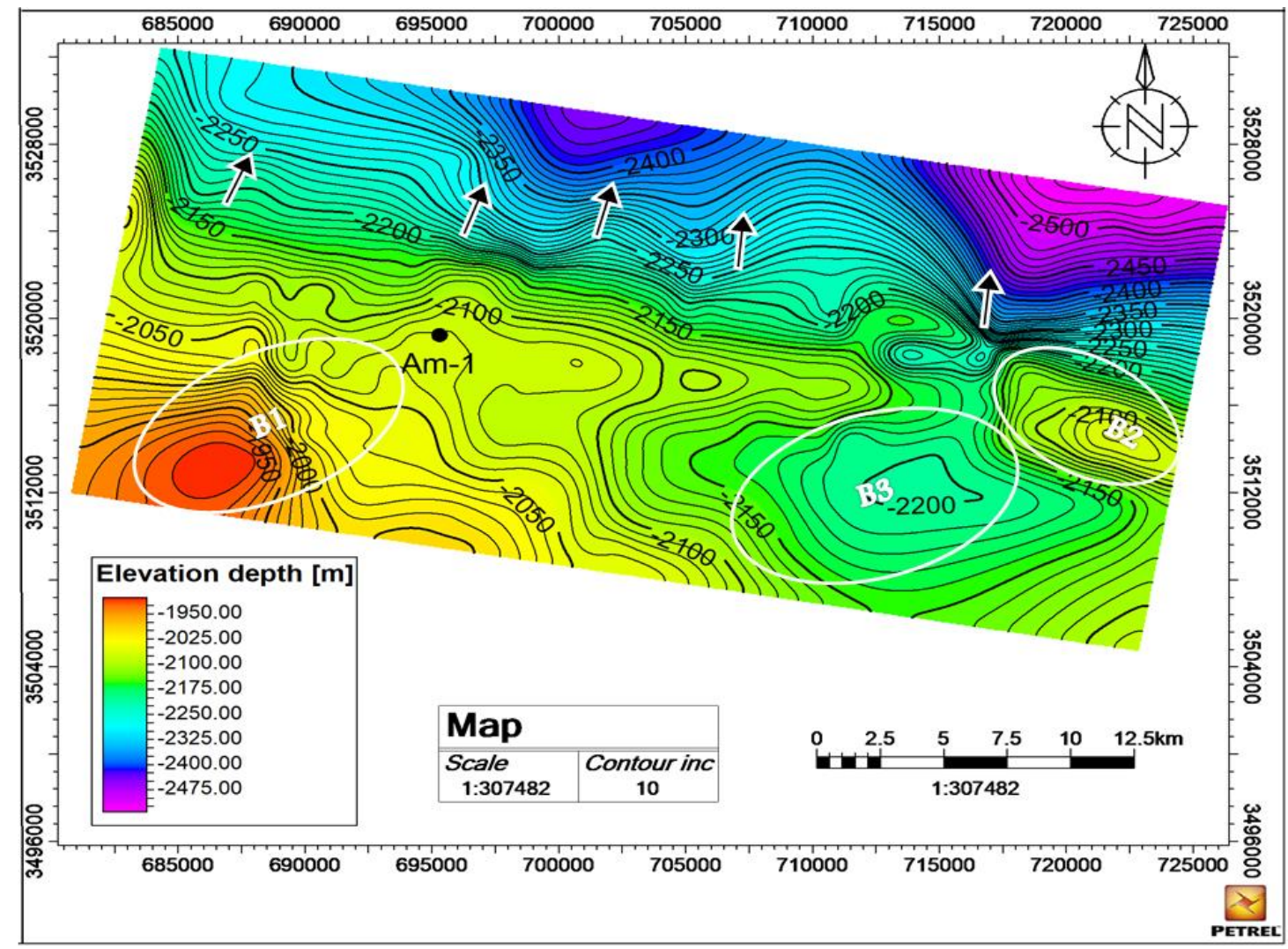

Figure 7- Lower Kirkuk Formation depth map.

\section{Stratigraphic Interpretation}

It is important to investigate the parameters of the faults, reflector discontinuity, angular unconformity, pinch out, and onlap. The instantaneous phase information is critical for identifying and characterizing the limits of the continuation of the reflector [15].

Through the stratigraphic interpretation of Kirkuk reflectors, we identified the sedimentary conditions, searching for stratigraphic traps and evidence for the accumulation of hydrocarbon content. Evidence of the presence of hydrocarbon was inferred from the presence of the trap in the eastern part of the region (Figure 8), which is also adjacent to many fields, in addition to the presence of lenses and onlap (Figure 9). It is equivalent to the deposition of the sand from the Ahwaz member in Iran. Oil content of these fields is a result of their formation in the same sedimentary basin and period, and infers that they contain the same type of rock sediments and sedimentation conditions. 


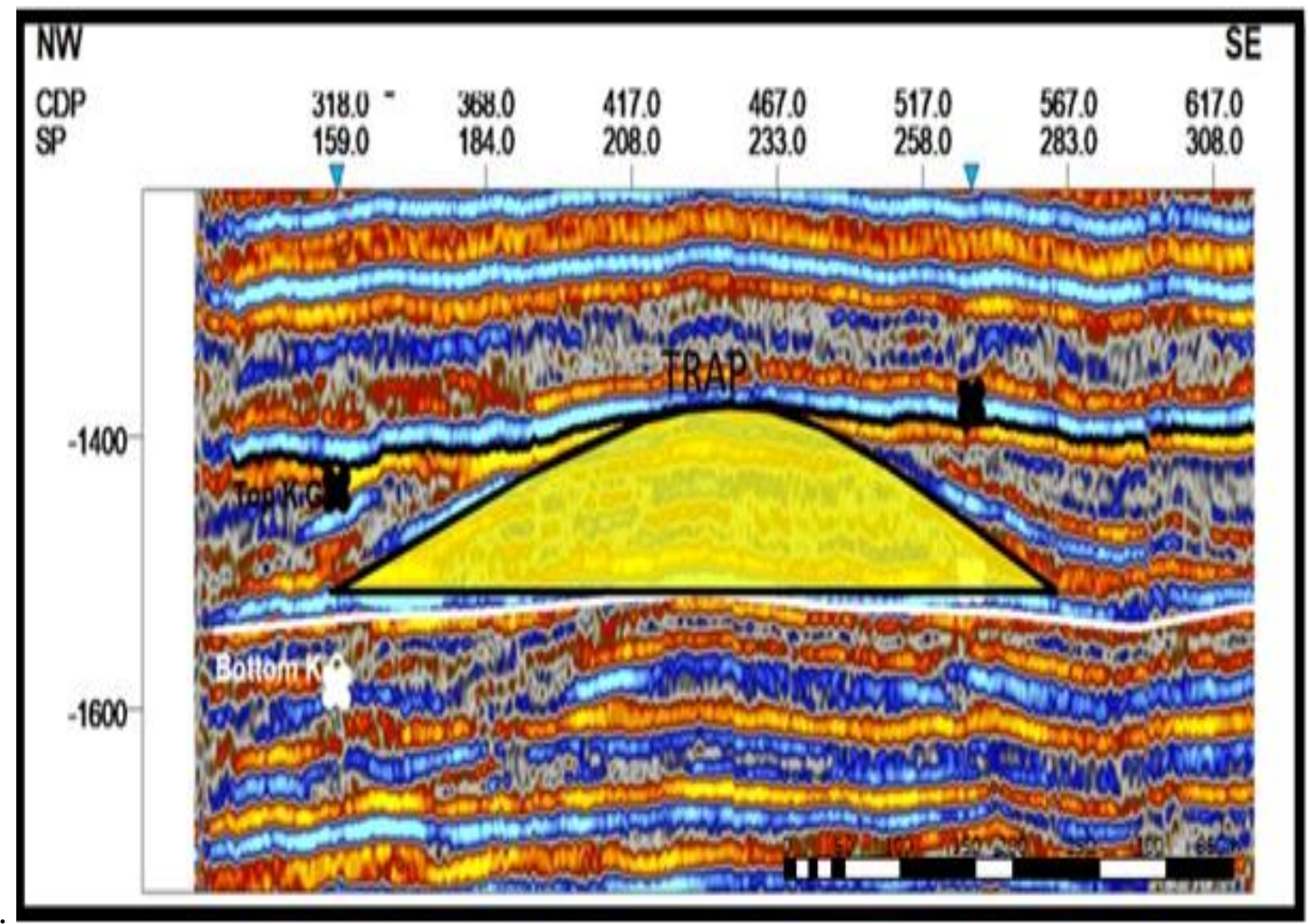

Figure 8- The stratigraphic trap in the seismic section.

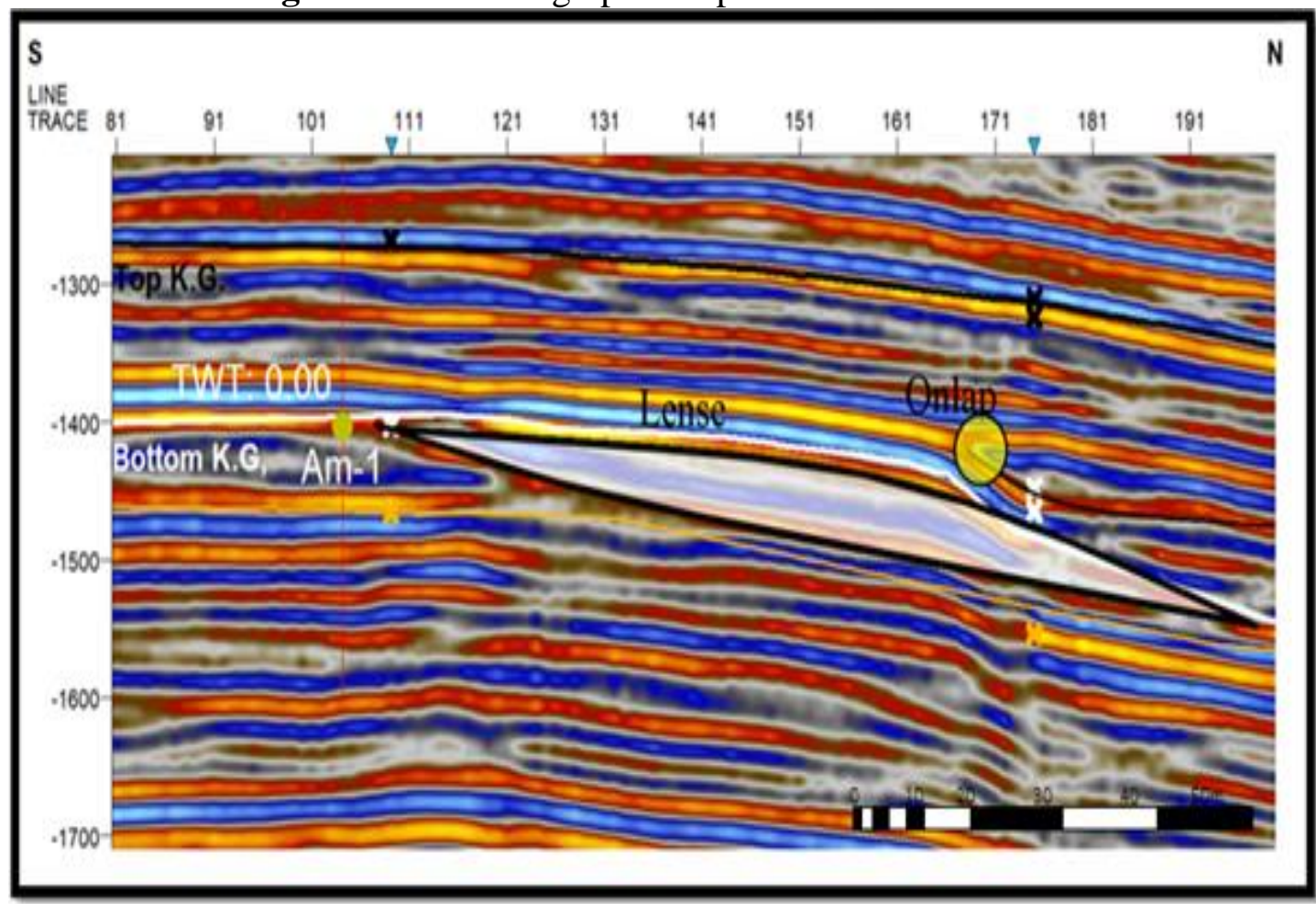

Figure 9- The onlap and lenses in the seismic section.

The instantaneous phase attribute is a very important tool to study faults, discontinuity, and angular unconformity of reflectors. It is also used to display the continuity of the seismic reflective surfaces [16]. By analyzing the reflectors, the occurrence of a seismic reflection mound structure was observed, as shown Figure 10. The presence of a mound (flat spot) may represent an evidence of hydrocarbon material accumulation. 


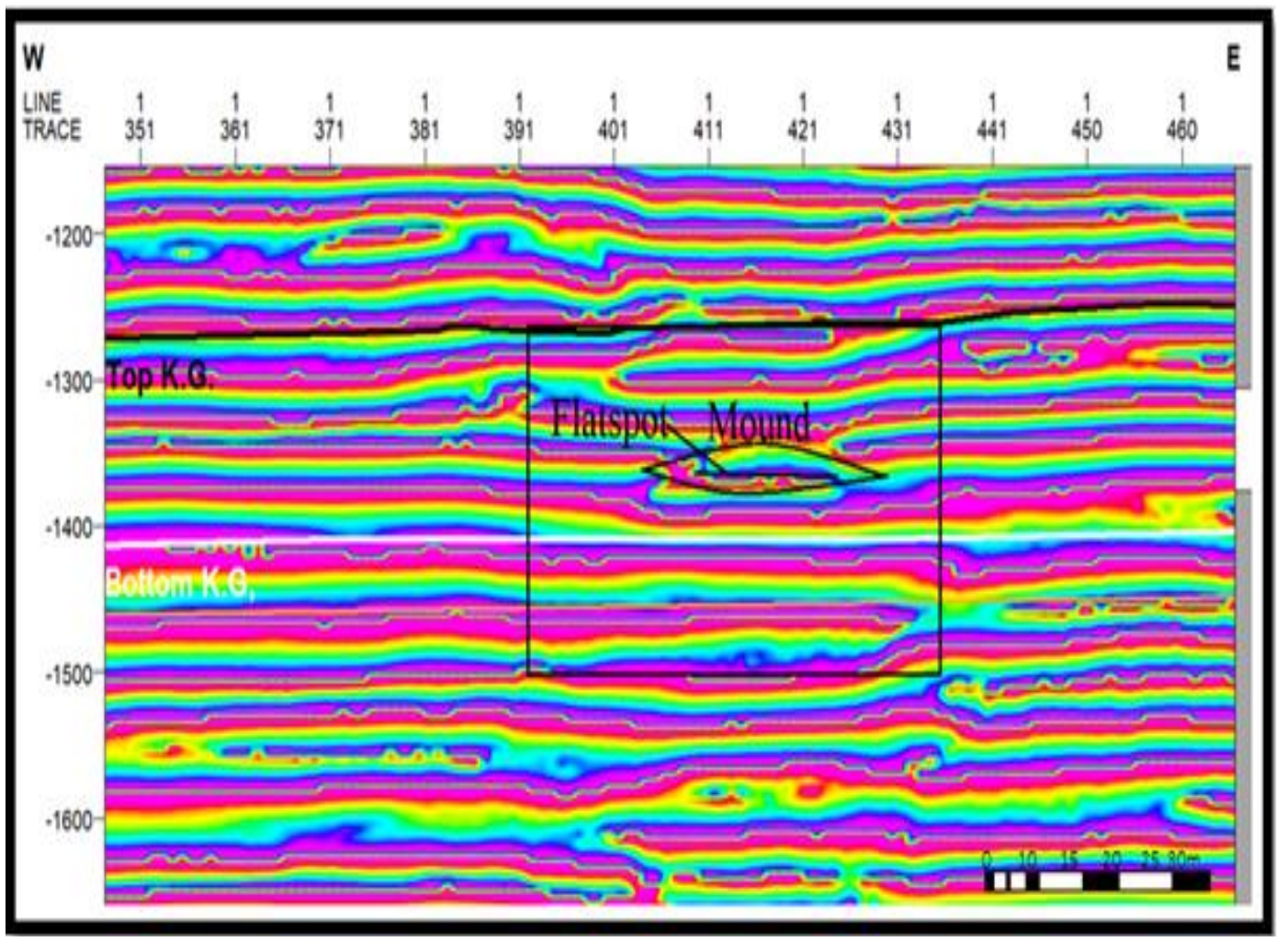

Figure 10- An instantaneous phase attributes showing the flatspot.

\section{Discussion}

Seismic interpretation of the Maysan group Formation, by using seismogram data and logging records (Am1), defined a two-reflector (top and bottom) Formation. Structural interpretation was explained by time and depth maps as well as stratigraphy attributes of the reflectors. The time and depth maps showed that the lowest depth values are at the southwest direction. This depth increases towards NE. Interpretation results showed the existence of three closure structures, which represent an anticline at the east, another anticline at the SE, and a nose structure (anticline) in the middle, extending from the East to the west.

The region is affected by faults that extend in the NE-SW direction. This direction is compatible with the general trend of faults, due to the collision of the Arabian and Iranian plates during the closure of Neo-Tethys. The stratigraphic interpretation for the seismic sections of Maysan group formation showed that it was deposited in a narrow basin during the beginning of the marine advance in the region to produce carbonate and with the sea receded. Sandstone was deposited from the Ga'ara formation, leading to an overlap between sediments, as well as the presence of sand lenses and onlap.

The current study shows the phase change in reflectors. It also demonstrates perfect results of hydrocarbon indexes. The results indicate the mound shape and the oil-water contact (flatspot). A stratigraphic trap in the middle and eastern parts of the Maysan Group Formation are also detected. It is proposed to rename the formation to Maysan Group, based on the name of the region, instead of the common name of Kirkuk Group in northern Iraq according to the environment of sedimentation which represents a mixture of clastic and carbonate facies and deposit pattern of low stand tract (LST).

\section{Conclusions}

Two reflectors were selected and detected as the top and base reflectors of Maysan Group. Count synthetic seismogram in Two-dimensional seismic reflection.

These horizons were followed over the entire area in order to illustrate structural and stratigraphic settings. 
The study revealed some closed structures, including the anticline in the East, the anticline in the Southeast, and the nose structure (anticline) in the middle of the study area, which extends toward the E-W direction. Faults were also detected by interpreting the results, which were extending in the NE direction.

Beside the stratigraphic traps which were found in the eastern part of the area, other structures were also distinguished in the same part, such as the lens, knee, and top overlap, which are potential indicators of hydrocarbon accumulation.

Good hydrocarbon indicators were distinguished in the middle and eastern parts of Maysan Group.

\section{References}

[1] Hart, B. S. Principle of 2D and 3D seismic interpretation, McGill University, 2004, 162p.

[2] Al-Sinawi, G. T. Introduction to Applied Geophysics, first ed., 1981, 142 p.

[3] Brown, A. R. Interpretation of Three-Dimensional Seismic Data (7 ed.). Tulsa, Oklahoma: The American Association of Petroleum Geologists and the Society of Exploration Geophysicists, 2011, $158 \mathrm{p}$.

[4] Alsadi, H. N. Seismic hydrocarbon exploration: $2 D$ and $3 D$ Techniques, springer international publishing, Switzerland, 2017, 331p.

[5] Milsom, J. Field Geophysics, 3rd. Ed. University College London, 2003, 232 p.

[6] Jawad, K. R and Medhat, E. N. "Petrophysical Properties and Reservoir Modeling of Mishrif Formation at Amara Oil Field, Southeast Iraq". Iraqi Journal of Science, vol. 58, no. 3A, pp. 1262-1272, 2017.

[7] Iraqi Petroleum Exploration Company (IPEC). Amara oil field, assessment. Maysan Oil Company, Dept. of Geology, 2010, 30 P.

[8] Maysan Oil Company. Report for Seismic proposes for Amara oil field, O.E.C Library. (Arabic interior report), 2006, 12p.

[9] Yacoub, S.Y. and Barwari, A. M. Quaternary Sediments Map of Iraq, scale 1: 1000 000, Explanatory Text. GEOSURV, Baghdad, Iraq pg36, 2002.

[10] Sharland, P. R., Casey, D. M., Davies, R. B., Simmons, M. D. Arabian Plate Sequence Stratigraphy. GeoArabia Special Publication 2, Gulf Petrolink, Bahrain, 2001, 371p.

[11] Al-Kadhimi, J., Sissakian, V.K., Fattah, A.S. and Deikran, D.B. Tectonic Map of Iraq, scale 1: 1000, 000, 2nd. ed., GEOSURV, Baghdad, Iraq, 1996.

[12] Jassim, S. Z. and Goff, J. C. Geology of Iraq, Dolin Prague and Moravian Museum, Brno, 2006, $228 \mathrm{p}$.

[13] Sissakian, V. K., \& Fouad, S. F. Geological map of Iraq, scale 1: 1000000. Iraq Geological Survey (GEOSURV) publications, Baghdad, Iraq, 2012.

[14] Kearey, P., Brooks, M., \& Hill, I. An Introduction to Geophysical Exploration, 3rd ed., Blackwell Science Ltd., 2002, pp. 81-82.

[15] Taner, M.T. and Sheriff R.E. "Application of amplitude, frequency and other attributes to stratigraphic and hydrocarbon exploration”. AAPG Memoir, vol. 26, pp. 301-327, 1977.

[16] Khorshid, S. Z. and Kadhm, A. D. "Subsurface Investigation of Oligocene Geologic Formations Age, East Baghdad Oil Field”. Iraqi Journal of Science, vol. 56, no. 4C, pp. 3441-3451, 2015. 